\title{
ESA eyes the attractions of small space missions
}

London. The European Space Agency (ESA) is considering the possibility of launching a series of relatively small space missions as one of a number of steps that might increase the cost-effectiveness of its space science programmes.

Speaking at a meeting in London last week organized by the UK Particle Physics and Astronomy Research Council (PPARC), Roger Bonnet, the director of the ESA programme, said that a study is also being made of the relative costs of ESA's administration of space projects compared to similar costs in the private sector.

$\mathrm{He}$ added that the agency was also looking at the costs of using the controversial juste retour principle in financing space missions, under which the 14 countries that contribute to ESA's budget have agreed that contracts worth at least 96 per cent of each country's subscription should be awarded to its national aerospace companies.

But Bonnet refused to make any concessions to ease the plight of British scientists who have been refused funds by PPARC to provide the payloads for the Integral gamma-ray satellite, even though this mission was initially suggested by astronomers from the United Kingdom (see Nature 373, 459; 1994)

ESA's existing and planned space missions fall into two categories: the so-called cornerstone missions, four of which form the foundation of its science programme Horizon 2000, and a series of medium-sized missions. The former cost a maximum of ECU600 million (US\$750 million) each, and the latter ECU345 million.

While acknowledging that large amounts of money are needed for major projects such as planetary missions, some scientists are concerned that they inevitably lock researchers into related fields of study reducing prospects for the pursuit of other scientific goals. Another concern is that budget constraints restrict the frequency of large and medium missions.

One suggestion at last week's meeting to compensate for both factors was that the European agency should consider launching a series of small missions costing around ECU50million, perhaps launching one every two years over a 20 -year period.

As an example of a successful 'small mission' - even if its price was slightly higher Leonard Culhane, director of the Mullard Space Science Laboratory, pointed out that the $380-\mathrm{kg}$ Yohkoh satellite launched by Japan in 1991 with a British instrument had "revolutionized" studies of the physics of the Sun (see figure). "I think that ESA would be wise to move in this direction," Culhane said.

In response, Bonnet pointed out that although ESA had been given a mandate to explore small missions three years ago, there had been little progress in defining what a small mission really is. "There is often a confusion between 'small' and 'cheap'," he said. "Furthermore, some seem to believe that a 'small' mission is merely a way of making a 'medium' mission cheaper."

Nevertheless, Bonnet said that the idea, which is already being studied by other agencies (including the US National Aeronautics and Space Administration), is now the subject of two separate studies within ESA, one a general assessment of the implications of such missions, the second a more detailed study of possible candidates.

A workshop on small missions, involving scientists, industrial representatives and members of ESA's science programme com-

\section{IMAGE UNAVAILABLE FOR COPYRIGHT REASONS}

Small is beautliful: a picture of the Sun taken by the 380-kg UK/Japan Yohkoh satellite.

mittee, is due to be held in the spring, with its conclusions being forwarded to the ESA council. Firm proposals are expected to be put to the ministerial meeting in October.

That meeting will also discuss the other moves Bonnet is making to increase the cost-effectiveness of ESA's space missions. The British government, for one, is keen to reassess the juste retour principle, still smarting at having lost the contract last year to build the X-ray satellite XMM to a German contractor because of this principle, despite having produced the most highly-rated bid (see Nature 371, 545; 1994).

But some British space scientists are worried that the United Kingdom may be painting itself into a corner, and will find itself isolated at the October meeting. For example, it appears that other countries may be prepared to pick up the contracts for the Integral payload dropped by PPARC. (In addition to Italy's extra support for the imaging telescope, Spain is said to be prepared to provide new funds for the optical transient camera.)

David Dickson

\section{Budget cuts will put Russian agency in 'critical' condition}

Moscow. As the US National Aeronautics and Space Administration celebrates last week's successful rendezvous with the Russian Mir space station, the director of the Russian Space Agency, Yuri Koptev, has said that financial problems facing the agency could lead it to curtail significantly the future operation of the space station.

Also under threat, said Koptev, are his agency's plans to launch 11 manned space flights. The agency's financial difficulties are the result of broad cuts on spending on research which are leaving the Russian space programme in a "critical" condition, he said.

The wider difficulties facing Russian science have been acknowledged by Boris Saltykov, the minister of science and technology policy, who criticized the lack of support from his government colleagues at a meeting of the State Duma (parliament)'s committee on education, culture and science.

According to Saltykov, science is now the lowest priority of 18 separate items in the national budget, and last year the scientific community received only 52 per cent of the funds allocated to it by the Duma. "All national leaders claim that science has priority in their policies," he said. "They should either openly acknowledge that they have changed their minds, or agree that their deeds do not match their words."

One result of the cuts is that state-owned scientific centres alone now face unpaid bills totalling 250 billion rubles (about US\$60 million). "We have been offered discounts on our electricity bills, but local authorities are reluctant to accept this decision as they have not received any special funds to cover the costs," said Saltykov.

Questioned about his decision to endorse the 1995 budget, Saltykov said he had been faced with two alternatives: to accept a budget promising large amounts of money for science, less than half of which was likely to materialize, or to accept a more modest budget with a high chance of it being met.

"Naturally we preferred the latter," he said. "Last year we were promised 5.1 thousand billion rubles, but only received 2.9 thousand billion rubles. This year's budget allocates 5.5 thousand billion rubles for science; if we really receive the money, the budget will have been doubled."

Yuri Osipov, the president of the Russian Academy of Sciences, said that although government spending will increase the academy's budget by 10 per cent next year, this is only half of what is needed.

Meanwhile, in an interview with the news agency Interfax, Koptev said that the draft 1995 budget allocated only 1,200 billion rubles for space exploration - about 40 per cent of the 1994 figure. 